\title{
PENINGKATAN KREATIVITAS KERJA GURU DENGAN MEMPERBAIKI BUDAYA ORGANISASI DAN EFIKASI DIRI
}

\author{
Fenni Sartana $^{a)}$, M. Entang ${ }^{b)}$, Yuyun Elizabeth Patras ${ }^{b *)}$, Sutji Harijanto $^{b)}$ \\ ${ }^{a)}$ Sekolah Menengah Kejuruan Amalia, Bogor, Indonesia \\ ${ }^{b)}$ Universitas Pakuan, Bogor, Indonesia \\ *)e-mail korespondensi: yuyun.elizabenth@unpak.ac.id
}

riwayat artikel : diterima: 17 November 2019; direvisi: 18 Desember 2019; disetujui: 16 Januari 2020

\begin{abstract}
Abstrak. Penelitian ini untuk mencari upaya meningkatkan kreativitas guru melalui pencarian hubungan antara budaya organisasi dan efikasi diri guru. Penelitian dilaksanakan di SMK Swasta se-Korwil Cibinong pada September tahun 2019. Populasi penelitian berjumlah 283 guru dan jumlah sampel sebanyak 166 guru. Pengumpulan data untuk setiap variabel yang diteliti menggunakan angket dengan skala likert. Teknik analisis menggunakan korelasi parsial dan korelasi ganda. Hasil penelitian menunjukkan terdapat hubungan positif antara budaya organisasi dengan kreativitas guru (koefisien korelasi ry $1=0,661$ dan koefisien determinasi $\mathrm{r} 2 \mathrm{y} 1=$ 0,437), terdapat hubungan positif antara efikasi diri dengan kreativitas guru (koefisien korelasi ry $2=0,609$ dan koefisien determinasi $\mathrm{r} 2 \mathrm{y} 2=0,370)$ serta terdapat hubungan positif dan sangat signifikan antara budaya organisasi dan efikasi diri secara bersama-sama dengan kreativitas guru (koefisien korelasi ry12 $=0,716$ dan koefisien determinasi r2y12=0,513). Penelitian ini merekomendasikan kreativitas guru dapat dioptimalisasikan melalui budaya organisasi dan efikasi diri baik secara parsial maupun bersama-sama.
\end{abstract}

Kata Kunci: Kreativitas guru, budaya organisasi, efikasi diri

\section{IMPROVING THE TEACHER CREATIVITY BY IMPROVING THE ORGANIZATION AND SELF-EFICATION CULTURE}

\begin{abstract}
The purpose of this reseach is to determine the correlation between organization culture and self efficacy toward teacher's creativity. This study is conducted in Vocational High School at Region of Cibinong. The study population is 283 teachers and the number of sample is 166 teachers decided by proportional random sampling. Data was collected by questionnaire. The data analysis technique used correlation regression partial and multiple. The result shows that there is positive correlation between organization culture and teacher's creativity (the correlation coefficient ry $1=0,661$ and the detemination coefficient $r 2 y 1=0,437$ ), there is positive correlation between self efficacy and teacher's creativity (the correlation coefficient ry $2=0,609$ and the determination coefficient $\mathrm{r} 2 \mathrm{y} 2=0,370$ ), and there is positive correlation of organization culture and self efficacy to teacher's creativity (the correlation coefficient ry12 $=0,716$ and the determination coefficient $\mathrm{r} 2 \mathrm{y} 12=0,513$ ). Based on the result, it can be concluded that the teacher's creativity could be enhanced through organization culture and self-efficacy either partially or concurrently
\end{abstract}

Keywords: teacher's creativity, organization culture, self-efficacy.

\section{PENDAHULUAN}

Kreativitas guru merupakan salah satu faktor yang mendukung pencapaian tujuan pendidikan agar menghasilkan lulusan yang berkualitas. Jika kreativitas guru rendah maka proses pembelajaran akan terasa monoton sehingga membuat siswa kurang tertarik dalam pembelajaran. Kreastivitas guru yang kurang akan mengakibatkan siswa kurang fokus pada saat proses pembelajaran sehingga tujuan pendidikan dalam menghasilkan lulusan berkualitas tidak tercapai. Keadaan di lapangan menunjukan bahwa kreativitas guru dalam menyelenggarakan pembelajaran di SMK se-Korwil Cibinong masih belum optimal. Atas dasar itu maka diperlukan upaya-upaya untuk meningkatkan kreativitas guru, khususnya guru SMK.

Dari teori para ahli tentang kreativitas diantaranya Colquit (2011: 306-307) bahwa kreativitas adalah penggunaan ide-ide baru dalam bekerja, memecahkan masalah dan melakukan tindakan-tindakan inovatif. Gibson et al. (2006: 119-120) mendefinisikan kreativitas sebagai perwujudan ide atau gagasan yang unggul dalam bentuk peluang atau produk usaha. Schermehorn et al. (2010: 222) menjelaskan kreativitas adalah proses melahirkan ide cemerlang atau pendekatan unik dalam pemecahan masalah atau eksploitasi peluang. Trnova dan Trna (2014) mengungkapkan bahwa guru kreatif selalu menggunakan berbagai strategi mengajar dan berbagai alat peraga dalam mengajar untuk merangsang dan menarik perhatian peserta didiknya.

Dari teori para ahli dapat disintesiskan bahwa Kreativitas guru adalah pengaktualisasi ide-ide yang dimiliki untuk menggali potensi berupa tindakan senang mempelajari hal-hal baru dituangkan dalam bentuk berpikir fleksibel melalui rasa ingin tahu yang besar baik menciptakan lingkungan kelas bervariasi maupun maupun menyelesaikan masalah sehingga menghasilkan karya yang bermanfaat. Indikator yang terdapat dalam kreativitas guru: 1) mempelajari hal-hal baru, 2) Berpikir fleksibel, 3) rasa ingin tahu yang besar, 4) lingkungan kelas, 5) penyelesaian masalah. 
Budaya Organisasi menurut Luthan (2011: 72) merupakan bentuk pemahaman nilai-nilai dan norma-norma yang penting dalam organisasi, yang mengarahkan perilaku anggota organisasi. Wibowo (2011: 19) menyatakan bahwa budaya organisasi merupakan filosofi dasar bagi organisasi yang berisi keyakinan, norma-norma dan nilai-nilai bersama yang menjadi karakteristik utama tentang bagaimana cara melakukan sesuatu dalam organisasi.

Edgar Scheein, dalam Gibson et al, (2006:108-109) budaya organisasi adalah suatu pola asumsi dasar yang tebentuk, terwujud dan dikembangkan oleh anggota-anggota organisasi untuk menanggulangi masalah-masalah adaptasi terhadap faktorfaktor eksternal dan untuk integrasi faktor-faktor internal organisasi. Organisasi berfungsi untuk menciptakan rasa identitas bagi anggota organisasi, memfasilitasi munculnya kolektif komitmen anggota organisasi, meningkatkan sistem sosial stabilitas, dan menciptakan mekanisme makna serta kontrol yang memandu sikap dan perilaku anggota organisasi (Suchyadi, 2017). Budaya organisasi mengandung mekanisme bahwa pola asumsi dasar menjadi landasan terbentuknya nilai-nilai dan norma-norma pada anggota organisasi, kemudian memberikan arah terhadap metode kerja dan perilaku anggota dalam organisasi.

Ivancevich (2010: 119-120) mendefinisikan bahwa budaya organisasi merupakan sebuah sistem makna kebersamaan yang dianut oleh para anggotanya dan inilah yang membedakan satu organisasi dengan organisasi lainnya. Sintesis budaya orgnisasi sendiri adalah nilai-nilai dan norma-norma yang menjadi dasar terwujudnya perilaku, peraturan-peraturan.

Bandura (2001: 78) menyatakan bahwa efikasi diri merupakan keyakinan seseorang terhadap kemampuannya untuk mengatur dan melaksanakan tindakan yang diperlukan untuk mengelola situasi. Lebih lanjut dijelaskan bahwa efikasi diri merupakan penilaian yang dibuat oleh seseorang tentang kemampuan dirinya untuk melaksanakan sejumlah tindakan terkait dengan situasi tertentu yang dihadapinya. Mencerminkan seberapa besar usaha seseorang dan seberapa kuat ketahanan seseorang menghadapi rintangan maupun tekanan (Wagner dan Hollenback (2010: 93-94).

Santrock (2008: 244-255) mendefinisikan efikasi diri merupakan keyakinan bahwa seseorang dapat menguasai situasi dan menciptakan hasil yang positif. Efikasi diri menentukan cara seseorang bersikap dan menghadapi tindakan dalam sebuah situasi. Keyakinan diri bahwa ia mampu menguasai situasi; keyakinan bahwa ia mampu menghasilkan sesuatu yang positif. Stephen (2014: 228-230) menyatakan bahwa efikasi diri bagian dari teori kognitif sosial atau teori pembelajaran sosial, mengacu pada keyakinan seseorang bahwa ia mampu melakukan tugas dengan baik.

Dari teori para ahli Efikasi diri dapat disintesiskan sebagai norma-norma perilaku yang mengandung nilai -nilai yang disepakati oleh para anggota yang dijadikan peraturan yang berlaku dan dijadikan pembiasaan dan dijadikan penyelesaian masalah-masalah dalam organisasi.

\section{METODE PENELITIAN}

Penelitian ini menggunakan metode kuantitatif dengan metode survey korelasional. variabel bebas dalam penelitian ini yaitu Budaya Organisasi (X1) dan Efikasi Diri (X2), sedangkan variabel terikat (Y) adalah Kreativitas Guru. Populasi dalam penelitian ini yaitu Guru di SMK Swasta di Korwil Cibinong. Sampel penelitian ini ditentukan sebanyak 166 dengan menggunakan rumus Slovin. Pengambilan sampel pada masing-masing sekolah dilaksanakan dengan teknik propotional random sampling. Data hasil penelitian kuntitatif dianalisis menggunakan statistik deskriptif dan statistik inferensial. Statistik inferensial yang menggunakan analisis regresi-korelasi. Analisis data diawali dengan analisis persyaratan analisis, yaitu: uji normalitas galat taksir dan uji hogenitas varian.kemudian dilanjutkan dengan penetapan persamaan regresi, uji signifikansi persamaan regresi, linearitas regresi serta pengujian hipotesis dengan uji korelasi menggunakan tabel ANAVA. Hasil data di lapangan pun akan dikelompokkan per indikator sehingga dapat dibandingkan dan dianalisis dengan menggunakan metode SITOREM (Hardhienata, 2017)

\section{HASIL DAN PEMBAHASAN}

\section{Hubungan Positif Antara Budaya Organisasi dengan Kreativitas Guru}

Hasil dari pengujian hipotesis tentang hubungan antara budaya organisasi dengan kreativitas guru menunjukkan bahwa nilai kekuatan hubungan $\mathrm{r}_{\mathrm{y} 1}$ sebesar 0,661 yang artinya kekuatan hubungannya cukup kuat, dan nilai koefisien determinasi $\mathrm{r}_{\mathrm{y} 1}^{2}$ sebesar 0,437 yang artinya Budaya Organisasi memberi kontribusi dalam peningkatan Kreativitas Guru sebesar 43,7\%.

Signifikansi hubungan antara antara budaya organisasi dengan kreativitas guru ditunjukkan dari hasil yang sangat signifikan pada taraf signifikansi $\alpha=0,05$ dan $\alpha=0,01$. Hal tersebut dapat dibuktikan pada hubungan fungsional antara Budaya Organisasi dengan Kreativitas Guru yang ditunjukkan oleh persamaan regresi $\hat{Y}=48,292+0,686 X_{1}$ artinya setiap kenaikan satu unit skor Budaya Organisasi dapat meningkatkan skor Kreativitas Guru sebesar 0,686 pada konstanta 48,292. Hasil penelitian ini didukung oleh jurnal dari Morteza Dousti, Seyyed Gafar Moosavi, dan Zynab Yousfi (2013: 1394-1398) yang berjudul "Study of Relationship between Organizational Culture, Organizational Commitment and Creativity of Physical Education Secretaries in Mazandaran Province" memberi kesimpulan bahwa terdapat hubungan positif yang signifikan $(\mathrm{r}=$ $0,84 \mathrm{p}<0,05)$ antara budaya organisasi dengan kreativitas. Semakin tinggi tingkat budaya organisasi, diprediksi akan tinggi pula tingkat kreativitas. 
Berdasarkan deskripsi di atas, maka budaya organisasi merupakan salah satu faktor penentu dalam peningkatan kreativitas guru. Ini berarti pula untuk meningkatkan kreativitas harus ditingkatkan budaya organisasi.

Tabel 1. Analisis Varians (ANAVA) dengan Persamaan regresi $\hat{Y}=28,856+0,804 X 1$

\begin{tabular}{l}
$\begin{array}{l}\text { Sumber } \\
\text { Varians }\end{array}$ \\
\hline Total (T)
\end{tabular}

\section{Hubungan Positif Antara Efikasi Diri dengan Kreativitas Guru}

Memperhatikan dari hasil analisis data diperoleh nilai korelasi efikasi diri dengan kreativitas guru yaitu sebesar $r_{y 2}=$ 0,609 dan koefisien determinasi $\mathrm{r}_{\mathrm{y} 2}^{2}=0,370$. Artinya bahwa terdapat hubungan positif antara efikasi diri dengan kreativitas guru yang memiliki hubungan yang cukup kuat. Efikasi Diri memberikan kontribusi sebesar 37,0\% dalam peningkatan kreativitas Guru.

Signifikansi hubungan efikasi diri dengan kreativitas guru diperoleh hasil yang sangat signifikan pada taraf signifikansi $\alpha=0,05$ dan $\alpha=0,01$. Terdapat hubungan yang positif antara efikasi diri dengan kreativitas guru. Hal ini dapat dilihat pada hubungan fungsional antara Efikasi Diri dengan Kreativitas Guru yang ditunjukkan oleh persamaan regresi $\hat{Y}=50,621+$ $0,651 \mathrm{X}_{2}$. Arti dari persamaan tersebut bahwa setiap kenaikan satu unit skor Efikasi Diri guru dapat meningkatkan skor Kreativitas Guru sebesar 0,651 pada konstanta 50,621.

Tabel 2. Analisis Varians (ANAVA) dengan Persamaan regresi $\hat{Y}=50,621+0,651 \mathrm{X}_{2}$

\begin{tabular}{|c|c|c|c|c|c|c|c|}
\hline $\begin{array}{c}\text { Sumber } \\
\text { Varians }\end{array}$ & \multirow{2}{*}{$\mathrm{dk}$} & \multirow{2}{*}{$\mathrm{JK}$} & \multirow{2}{*}{ RJK } & \multirow{2}{*}{ Fhit } & \multicolumn{2}{|c|}{ Ftabel } & \multirow{2}{*}{ Kesimpulan } \\
\cline { 6 - 7 } & & & & & 0.05 & 0.01 & \\
\hline Total (T) & 166 & 2940176 & 2940176 & & & & \\
\hline Regresi (a) & 1 & 2898195 & 2898195 & & & & \\
\hline Regresi (b/a) & 1 & 15545.81 & 15545.81 & $96.44^{* *}$ & 3.90 & 6.79 & Sangat Singnifikan \\
\hline Sisa (S) & 164 & 26435.27 & 161.1907 & & & & \\
\hline Tuna Cocok & 39 & 10069.1 & 258.1821 & $1.07^{\text {ns }}$ & 1.50 & 1.76 & Linear \\
\hline Galat & 125 & 16366.17 & 130.9294 & & & & \\
\hline
\end{tabular}

Hasil penelitian ini didukung oleh Nur Khayati SMA Negeri 1 Cikarang Utara dan Sri Sarjana SMK Negeri 1 Cikarang Barat yang bertema tentang efikasi diri menunjukan bahwa efikasi diri berpengaruh positif terhadap kreativitas guru. Hal ini berarti bahwa guru yang memiliki efikasi diri yang tinggi akan dapat meningkatkan kreativitas guru. Berdasarkan deskripsi di atas, maka efikasi diri guru merupakan salah satu faktor penentu dalam peningkatan kreativitas guru.

\section{Hubungan Positif Antara Budaya Organisasi dan Efikasi Diri secara bersama-sama dengan Kreativitas Guru}

Hubungan budaya organisasi dan efikasi diri secara bersama-sama dengan kreativitas Guru, memiliki koefisien korelasi sebesar $\mathrm{r}_{\mathrm{y} 12}=0,716$ dan koefisien determinasi $\mathrm{r}_{\mathrm{y} 12}^{2}=0,513$ Berdasarkan temuan di atas dapat disimpulkan bahwa $51,3 \%$ kreativitas Guru dapat ditingkatkan melalui variabel budaya Organisasi dan Efikasi Diri secara bersama-sama. Koefisien determinasi variabel Budaya Organisasi relatif lebih tinggi yaitu sebesar 43,7\% jika dibandingan dengan koefisien determinasi Efikasi Diri yaitu sebesar 37,0\%. Perbedaan terhadap perolehan nilai koefisien determinasi kedua variabel secara sendiri-sendiri tersebut memberikan makna bahwa berdasarkan penilaian reponden, faktor Budaya Organisasi memberikan sumbangan yang lebih positif dan signifikan bagi Kreativitas Guru. Sedangkan nilai koefisien determinasi variabel Budaya Organisasi dan Efikasi Diri guru secara bersama-sama memberikan nilai sebesar 51,3\%. Hal ini menujukkan makna bahwa menurut penilaian responden, kedua faktor Budaya Organisasi dan Efikasi Diri secara bersama-sama ternyata memberikan sumbangan yang sangat signifikan bagi peningkatan Kreativitas Guru.

Berdasarkan uraian di atas, maka Budaya Organisasi yang baik dan Efikasi Diri yang kondusif secara bersama-sama dapat meningkatkan Kreativitas Guru. Selain itu, untuk melihat seberapa besar kekuatan hubungan antara variabel bebas dan terikat serta untuk mendapat solusi optimal dari penelitian ini dan untuk melakukan optimasi terhadap masing-maing indikator setiap variabel penelitian dilakukan dengan pemberian bobot pada masing-masing indikator, berdasarkan hasil Teori 
Pengenalan Ilmiah untuk Riset Operasi di bidang Manajemen Pendidikan atau dikenal dengan SITOREM (Hardienata, S: 2017) seperti gambar 1

Tabel 3. ANAVA untuk uji signifikansi regresi ganda dengan persamaan $\hat{Y}=27,881+0,481 X_{1}+0,363 X_{2}$

\begin{tabular}{|c|c|c|c|c|c|c|c|}
\hline $\begin{array}{c}\text { Sumber } \\
\text { Varian }\end{array}$ & $\mathrm{dk}$ & $\mathrm{JK}$ & \multirow{2}{*}{ RJK } & Fhitung & \multicolumn{2}{|c|}{ Ftabel } & Kesimpulan \\
\hline & & & & & $\alpha=0,05$ & $\alpha=0,01$ & \\
\hline Total & 165 & 41981.08 & & & & & \\
\hline Regresi & 2 & 21539.54 & 10769.77 & $85.88^{* *}$ & 3.05 & 4.74 & Sangat Signifikan \\
\hline Sisa & 163 & 20441.54 & 125.41 & & & & \\
\hline
\end{tabular}
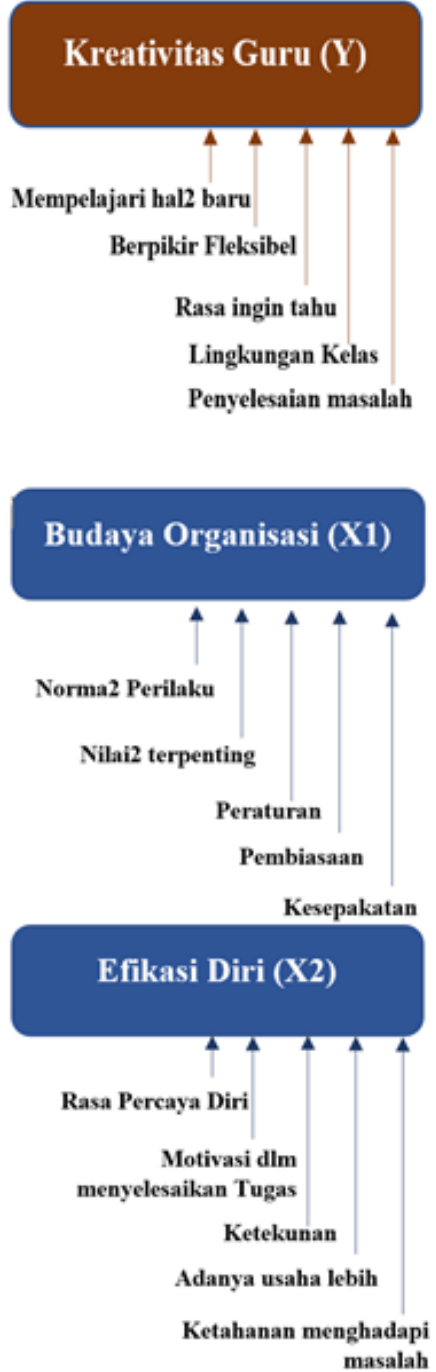

\section{вовот:}

1. Mempelajari hal2 baru $(28 \% \%)(3,8)$

2. Rasa ingin tahu $(22 \%)(3,8)$

3. Berfikir fleksibel $(18 \%)(3,8)$

4. Penyelesaian masalah $(17 \%)(4,0)$

5. Lingkungan kelas $(15 \%)(4,0)$

\section{BOBOT:}

1. Nilai-nilai terpenting $(25 \%)(3,9)$

2. Norma2 prilaku $(23 \%)(3,9)$

3. Pembiasaan $(20 \%)(3,8)$

4. Peraturan $(18 \%)(3,8)$

5. Kesepakatan $(14 \%)(3,7)$

\section{BOBOT:}

\section{Rasa Percaya Diri} $(24 \%)(3,7)$

2. Motivasi dlm menyelesaikan tugas $(21 \%)(3,8)$

3. Ketahanan menghadapi masalah $(20 \%)(3,7)$

4. Ketekunan $(18 \%)(3,8)$

5. Adanya usaha lebih $(17 \%)(3,7)$

$\quad$ PRIORITAS
UNTUK
DITINGKATKAN:
1. Mempelajari hal2
baru
2. Nilai2 terpenting
3. Rasa percaya diri
4. Norma2 prilaku
5. Rasa ingin tahu
6. Motivasi dalam
menyelesaikan tugas
7. Pembiasaan
8. Ketahanan
menghadapi masalah
9. Berfikir fleksibel
10. Peraturan
11. Ketekunan
12. Adanya usaha
lebih
13. Kesepakatan

Gambar 1. Hasil akhir dari optimasi terhadap faktor-faktor dari masing-masing variabel

\section{SIMPULAN}

Penelitian ini menyimpulkan: (1) Terdapat hubungan positif dan sangat signifikan antara budaya organisasi dengan kreativitas guru: (2) Terdapat hubungan antara efikasi diri dengan kreativitas guru; dan (3) Terdapat hubungan antara budaya organisasi dan efikasi diri secara bersama-sama dengan kreativitas guru. Berdasarkan hasil penelitian ini maka untuk meningkatkan kreativitas Guru dapat dilakukan dengan penguatan budaya organisasi dan efikasi diri. 


\section{REFERENSI}

Bandura, Albert. (2001). Self-Efficacy: The Exercise of Control. New York: WH Freeman and Company.

Colquit, J.A., J.A Lepine, \& M.J. Wesson. (2011). Organizational Behavior. New York: McGraw-Hill.

Gibson, J.L. et al. (2006). Organization: Behavior, Structure and Processes. New York: McGraw-Hill.

Hardhienata. (2017). The Development of Scientific Identification Theory to Conduct Operation Research in Education. IOP Conf. Series: Material Science and Engineering. 166012007.

Ivancevich, John M. (2010). Human Resource Management $11^{\text {th }}$ Edition. New York: McGraw-Hill.

Luthan, Fred. (2011). Organizational Organizational An Evidence-Based Approach. New York: McGraw-Hill.

Morteza Dousti, Seyyed Gafarmoosavi, Zynab Yousfi. (2013) Study of relationship between organizational culture, Organizational Commitment and creativity of Physical Education Secretaries in Mazandaran Province. International Research Journal of Applied and Basic Sciences. Vol, 5(11): 1394-1398

Khayati, Nur \& Sarjana, Sri. (2015). Efikasi Diri dan Kreativitas Menciptakan Inovasi Guru. Jurnal Pendidikan dan Kebudayaan. 21. 243. 10.24832/jpnk.v21i3.189.

Santrock, J.W. (2008). Educational Psycology. New York: Mc Graw-Hill.

Schermehorn, JR., James G. Hunt, Richard N.Osborn, Mary Uhl Bien. (2010). Organizational Behavior. New York: John Wilet \& Sons Inc.

Stephen, Robbins, P., dan Judge, Timothy A. (2014). Perilaku Organisasi: Organizational Behavior (Buku 1) (Edisi 9), Jakarta: Salemba Empat.

Suchyadi, Y. (2017). Relationship between Work Motivation and Organizational Culture in Enhancing Professional Attitudes of Pakuan University Lecturers. Journal Of Humanities And Social Studies, 01(01), 41-45. https://doi.org/10.33751/jhss.v1i1.372

Trnova and Trna. (2014). Implementation of Creativity in Science Teacher Training. International Journal on New Trends in Education and Their Implications. Volume 5 No 3:54-55

Wagner and Hollenback. (2010). Organization Behavior: Securing Competitive Advantage. London: Routledge.

Wibowo. (2011). Budaya Organisasi. Jakarta: PT Raja Grafindo Persada. 